\title{
Development and Validation of Supervision Scale in Phone Consultation in Iran
}

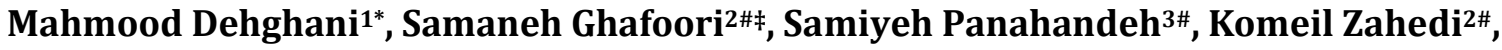 \\ Nahid Honarmand ${ }^{4 \#}$, Arezo Zokaeefar ${ }^{5 \dagger}$
}

\begin{abstract}
${ }^{1}$ Clinical Psychology at Center of Excellence in Psychiatry and Clinical Psychology, School of Behavioral Sciences and Mental Health (Institute of Tehran Psychiatric), Iran University of Medical Science, Tehran, Iran

${ }^{2}$ Clinical Psychology, School of Behavioral Sciences and Mental Health (Tehran Institute of Psychiatry) and the Center of Excellence in Psychiatry and Clinical Psychology, Iran University of Medical Sciences, Tehran, Iran

${ }^{3}$ Clinical Psychology at Department of Clinical Psychology, University of Social Welfare and Rehabilitation Sciences, Tehran, Iran

${ }^{4}$ Educational psychology at The Islamic Azad University, Science and Research Branch, Tehran, Iran

${ }^{5}$ State Welfare Organization of Iran, Tehran, Iran

Email: dehghani.m@iums.ac.ir, 'ghafoori.s@tak.iums.ac.ir, Sa.Panahandeh@uswr.ac.ir,

Zahedi.k@tak.iums.ac.ir, nahidhonarmand@gmail.com, zokaee2477@yahoo.com
\end{abstract}

How to cite this paper: Dehghani, M., Ghafoori, S., Panahandeh, S., Zahedi, K., Honarmand, N. and Zokaeefar, A. (2017) Development and Validation of Supervision Scale in Phone Consultation in Iran. Open Journal of Medical Psychology, 6, 144-152.

https://doi.org/10.4236/ojmp.2017.62012

Received: January 6, 2017

Accepted: April 25, 2017

Published: April 28, 2017

Copyright (c) 2017 by authors and Scientific Research Publishing Inc. This work is licensed under the Creative Commons Attribution International License (CC BY 4.0).

http://creativecommons.org/licenses/by/4.0/

\begin{abstract}
The purpose of the present research is to develop and validate an instrument for supervision in phone consultation. Literature review and focus group discussion in the first stage led to the extraction of twenty items for the supervision scale. After the initial administration and the group work of the specialized team and upon receiving the feedback, the repetitive and overlapping items were deleted and ten important items were selected. Finally, the instrument was administered on 499 consolers of phone consultation in 19 provinces of Iran, consisted of male and female individuals cooperating in the counselor's voice. The consolers were trained and assessed by 96 supervisors. The supervisors consisted of male and female supervisors introduced as supervisors by the State Welfare Organization of Iran in different provinces all over the country. This study was conducted in State Welfare Organization of Iran. The exploratory factor analysis on the supervision scale revealed two dimensions: therapeutic alliance and intervention. The result showed the supervision scale was a valid and reliable instrument for assessing the consultation process in the semi-structured model of phone consultation. The finding is in line with previous studies in terms of therapeutic alliance, intervention in the semi-structured model of phone consultation.
\end{abstract}

\footnotetext{
*Assistant Professor.

\#PhD Student.

${ }^{\dagger}$ State Welfare Organization of Iran, Master degree in General Psychology Tehran, Iran
} 


\section{Keywords}

Supervisor, Supervision, Phone Consultation

\section{Introduction}

Since the beginning of the history of psychotherapy, the importance of supervision as the process of an expert's supervision on a beginner's work has been clear to the pioneers of this field. We can find instances in the work of [1]. Although the history of supervision like every other field of science is full of ups and downs, there is no doubt about the importance and critical role of supervision in increasing competency in trainees, counselors and novice therapists. In addition, supervision has always played a substantial part in the quality control of mental health services and is considered as a gateway for the entrance of individuals into a special field.

Supervision is an intervention provided by a more experienced professional for a less experienced member in the same profession [2]. The purpose of supervision is to supervise the quality of the professional services provided to clients and to control the gateway of people's entrance to a profession.

Today, there are numerous approaches in supervision like psychotherapy approach, psychodynamics approach, cognitive-behavioral approach, client-based approach, developmental integrative approach, integrative approach and systemic approach.

Today, the importance of supervision has increased due to the increase in the target population, consultation and psychotherapy approaches and the different methods of providing therapeutic services such as face-to-face consultation, phone consultation, etc. Given the limitations of the modern life, one of these methods that have grown is the phone consultation. Phone consultation is a kind of consultation in which counselors and trained individuals address a caller's crises or personal problems [3]. Phone consultation was presented by crisis intervention and suicide prevention centers early in 1960s and it was the necessity, accessibility and cheapness of this method that led to the increasing use of such services [4]. Today, there are lots of phone consultation lines all over the world providing different services such child advice lines and other services [5].

The first phone consultation line in Iran was established in 1993 under the title of "counselor's voice" with the help of the State Welfare Organization of Iran, first in Tehran and then in other provinces [6]. After several years, [7] evaluated the satisfaction from phone consultation and developed a structure for that based on [8] [9] [10] [11]. Also, they used studies for developing the structure, such as [12] [13] [14]. In their research, they presented a semi-structured phone consultation, including general components of consultation and specific method to phone consultation in Iran. It has the following stages: Establishment of a relationship, conceptualization of the caller's problem, evaluation of the usefulness of the phone consultation, pursuing referral consultation approach if the phone consultation is not useful, and pursuing strategic, problem-based or 
supportive approach if the phone consultation is useful. This paradigm included the following preliminary stage of phone consultation: introduction of the center at the beginning of the conversation, no use of unprofessional words, follow-up of the caller's main complaint, gathering information based on a purposeful process, use of examples, avoidance of immature intervention, developing hypothesis, flexible maintenance of an approach, to be an active listener, empathy, acceptance, avoidance of judgment and advice.

The intermediate stage of consultation process includes the following stages: conceptualization of the patient's problem, goal setting in the consultation process, proportionality in the counselor' and the caller's talking time, avoidance of deviating from the main point, no use of English words, use of Socratic conversation, handling the sexual callers, avoidance of peremptory talk with clients or making decisions for them, flexible maintenance of structure in the consultation process.

The final stage of phone consultation process included the following: stating concluding words at the end of consultation process, no sudden termination, necessity of preparation, proportionality in the preliminary, intermediate and final consultation processes, management of the consultation time, confident and respectful statement of the necessity of referral in vulnerable cases, adoption of a problem-based and strategic approach, adoption of a supportive and communicative approach in the emotional problems, introduction of the consoler as well as stating the counselor's code, informing the center's head about critical cases.

In referral consultation, it was necessary to take the following steps: adoption of a communicative, strategic and supportive approach, preparation of the caller through talking about the limitations of phone consultation, providing general information about the caller's problem, "avoidance from labeling", emphasis on the necessity of visiting an expert while having an optimistic viewpoint, encouraging callers and helping them to find a confidant and trustful clinic, introduction of the consoler as well as stating the counselor's code for further guidance.

In spite of many years passing since the time phone consultation services were presented, the great budget designated for it, the number of counselors involved in this process and the special target group, there is no evaluation system for the quality control of phone consultation services. Lack of appropriate attention to the structure and process of phone consultation, results in recession and lack of motivation in counselors which leads to the decreased quality of phone consultation and the weakened status of phone consultation. Our effort in present research is promoting the services provided by phone counselors as well as developing and validating a scale based on semi-structured phone consultation and several focus groups discussion, in order to control the quality and increase the competency in counselors.

\section{Method}

\subsection{Participants}

We informed the supervisor and supervisees that participating in this research 
and all of them fill in the consent form. Also we informed the whole number of the callers to counselor's voice and they gave their consent for participating in a research study. We obeyed the rule of confidentiality and analyzed the data by the code that assigned for each participant.

The statistical population included all psychologists and counselors that were working in the phone counselor's voice program in the State welfare Organization of Iran. 96 supervisors and 499 consolers participated in this study. The supervisors consisted of male and female introduced as supervisors by the State welfare Organization of Iran in different provinces all over the country. They had participated in three two-day workshops of training supervision in phone consultation. The consolers were trained by supervisors who learned semistructured phone consultation. The scale was administered in 499 consolers of phone consultation in 19 provinces. The consolers sample consisted of male and female individuals cooperating in the counselor's voice. Almost everybody participating in the State welfare Organization of Iran's counselor's voice as counselor or psychologist took part in this research.

\subsection{Procedure}

The supervision scale was the research instrument that we designed it based on semi-structured phone consultation and several focus groups discussion. For developing and validating this questionnaire, we selected 20 items in the early investigation, based on the important texts mentioned above [15] [16] [17] [18] [19].

Then, via a pilot study and focus group discussion with three two-day workshops by an expert team, we merged or deleted the items that overlapped, and finally selected 10 items for the final instrument. We placed the responses in the 5-point Likert type scale. 100 psychologists and counselors have participated in the process of questionnaire preparation and we did the essential adjustments. The supervision scale included the factors of being a good listener, understanding and empathy, clarification, maintenance of a purposeful process and hypothesis development, collaborative attitude and flexibility, provision of a secure and non-judgmental atmosphere, time management, appropriate intervention or referral, stating concluding words and giving feedback, preparation and no sudden termination. We should mention that in any phone consultation session, the supervisor assessed consoler's intervention based on this scale.

\section{Results}

The scale was administered on 499 consolers of phone consultation in 19 provinces. The most consolers were in Qom Province (44 consolers) and the least consolers were in Hamedan Province (4 consolers). In the supervision scale, $\mathrm{M}=$ $43 / 16$ and $\mathrm{SD}=5 / 09$. Ardebil Province gained the highest mean (48.97) in the supervision scale.

For determining the internal consistency of the scale items in the research, we used the Cronbach's alpha. The Cronbach's alpha for the supervision scale was 0.871 . The value was higher than 0.7 and approved the reliability of the scale (Table 1). 
Table 1 . Scale reliability results.

\begin{tabular}{ccc}
\hline Scale & Number of items & Cronbach's alpha \\
\hline Supervision & 10 & 0.871 \\
\hline
\end{tabular}

For analyzing the data related to the supervision scale, we used the principal components analysis method using the rotational Varimax method and the scree plot. For investigating the appropriateness of the data, we used the Bartlett test of sphericity and for the purpose of the adequacy of the sample size; we used the Kaiser-Meyer-Olkin measure (Table 2).

Based on Table 2, the KMO value equals 0.895, which shows the appropriateness of the selected sample size in the supervision scale for the exploratory factor analysis. Moreover, the value of the Bartlett test of sphericity is significant. Therefore, the data are appropriate for the factor analysis. The result showed that all scale items are finally placed on two dimensions and account for 58.524 percent of the variance (Table 3 ).

Therefore, we extracted two dimensions out of the 10 items related to the supervision scale. The first dimension included 5 items and the second dimension included 2 items.

\section{Discussion}

The present research dealt with the development and validation of an instrument for supervision in phone consultation. The result showed that the supervision scale was a reliable and valid instrument for the evaluation of phone consultation. Since no instrument had been designed in Iran to evaluate the phone consultation and the feedback to counselors in a semi-structured model of phone consultation, it was crucial to develop and validate an instrument that could evaluate the important dimensions of phone consultation and could provide an opportunity for giving feedback to counselors. Moreover, it is not possible to control the quality and increase the proficiency in counselors without access to a valid and appropriate instrument. Consequently, it is scientifically impossible for such a system to be useful when there is not any quality control.

In accordance with important [18] [19], the supervision scale showed that concentrating on therapeutic alliance was a necessary dimension in phone consultation. The therapeutic alliance dimension is in accordance with various studies that consider the therapeutic alliance to be the most valid predictor of positive therapy outcome regardless of the therapy approach adopted and consider it a factor in the continued relationship with mental health services [20] [21] [22] [23]. In addition, given the importance of this factor, various instruments have been designed for assessing the therapeutic alliance [15]. However, in none of these instruments, the therapeutic alliance in phone consultation is evaluated by the supervisor. Therefore, the present scale can be an appropriate method for evaluating therapeutic alliance in the context of phone consultation especially because this instrument evaluates the therapeutic alliance in the context of semistructured model of phone consultation for the purpose of structuring the consultation process. In addition, given the importance of supervision as a gateway 
Table 2. Bartlett test of sphericity and KMO measure of sampling adequacy.

\begin{tabular}{cc}
\hline Kaiser-Meyer-Olkin (KMO) measure of sampling adequacy & 0.895 \\
\hline Chi-Square value & $1878 / 969$ \\
Df & 45 \\
$P$ & 0.001 \\
\hline
\end{tabular}

Table 3. Factor loads base on the results of the exploratory factor analysis-supervision scale.

\begin{tabular}{lcc}
\hline Dimensions & Item number & Factor load \\
\hline \multirow{2}{*}{$\begin{array}{c}\text { Therapeutic } \\
\text { alliance }\end{array}$} & Being a good listener & 0.771 \\
& Understanding and empathy & 0.669 \\
& Clarification & 0.757 \\
& Providing a non-judgmental and secure space & 0.692 \\
& Eigen value & 0.576 \\
& Explained cumulative variance percentage & $4 / 697$ \\
& Maintaining a purposeful process and making hypotheses & $46 / 965$ \\
Time management (approximately 30 minutes) & 0.565 \\
Antervention & Appropriate intervention or referring & 0.756 \\
& Conclusion and giving feedback & 0.758 \\
& Preparation and avoidance of suddenly termination & 0.697 \\
& Eigen value & 0.789 \\
\hline Explained cumulative variance percentage & $1 / 156$ \\
\hline
\end{tabular}

to professional mental health services, the evaluation of this important dimension by the supervisor can be an important step toward teaching its elements to novice therapists. In the context where there is a limited time for phone consultation, therapeutic alliance can be an important factor in a successful phone consultation.

Another dimension of supervision scale was the intervention. Like face-to-face consultation, in phone consultation, the structure and process of intervention play a critical role. Lack of attention to this structure can result in the bewilderment of the counselor, lengthening of the duration of phone consultation and its uselessness, problem in discerning whether phone consultation or referral would be more efficacious, serious obstacles in conducting research on consultation process and in the proceeding of the scientific and clinical goals [3] [5] [6]. Following a semi-structured intervention model in phone consultation [12] gives the phone consultation session an appropriate and scheduled structure increases the caller's satisfaction, leads to the identification of clients who need face to face therapy and their referral to the most appropriate psychotherapy services through the development of a proper therapeutic alliance. Development of therapeutic 
alliance at the beginning of consultation sessions and following this intervention model can increase the clients' cooperation and make the referral process successful. Furthermore, increased satisfaction in callers can introduce to the public the phone consultation as a base for successful referrals and meet clients' needs.

Limitations and directions for further research:

This research like any other research faces some limitations. Given the phone consultation limitations in the present research (limitation in the duration of phone consultation and lack of non-verbal information), most interventions are designed based on semi-structured therapies such as cognitive-behavioral approach, and supportive and psycho-education approach and do not include other therapeutic approaches. Although in the educational pack of supervision and in the workshop series of supervision, the emphasis is on a range of approaches in order to present an integrative approach in supervision, the general components of consultation process are concentrated on in order to maintain a specified structure and to present an objective evaluation scale. Therefore, it is considered as one of the limitations of the present research and caution should be taken in the generalization of the present research results to other supervision models and face "to" face consultations. However, this scale emphasizes general components (such as therapeutic alliance, empathy, etc.) which facilitate generalization. Furthermore, it is an objective tool to evaluate consoler's intervention and his/her relationship with clients.

This research resulted from a need in a kind of theoretically valid psychometric instrument for the assessment of phone consultation process. Since the available instruments had some limitations, use of such instruments is a way to monitor phone consultation process. Future research can investigate the relationship among supervisory alliance, therapeutic consequences and supervision. Use of such scales can be useful in achieving this goal although assessing supervision consequences is a challenging task and use of self-report scales can lead to halo effect. In order to address this challenge, it is recommended to use objective instruments and double-blind researches on the supervisee performance in therapy and the resulted outcomes on clients.

Furthermore, evaluation of both participants' viewpoints is necessary in the supervision process. Future research can investigate the helpful and unhelpful supervision dimensions from the supervisee's perspective and the result can lead to the development of a kind of scale parallel to the therapeutic alliance. Such an instrument can be used to investigate the similarities and differences in both participants in supervision dyad.

\section{References}

[1] Alexander, L.B. and Luborsky, L. (1986) The Penn Helping Alliance Scales. In: Greenberg, L.S. and Pinsoff, W.M., Eds., The Psychotherapeutic Process. A Research Handbook, Guilford Press, New York, 325-366.

[2] Ardito, R.B. and Rabellino, D. (2011) Therapeutic Alliance and Outcome of Psychotherapy: Historical Excursus, Measurements, and Prospects for Research. Frontiers in Psychology, 2, 270. https://doi.org/10.3389/fpsyg.2011.00270 
[3] Martin, D.J., Garske, J.P. and Davis, M.K. (2000) Relation of the Therapeutic Alliance with Outcome and Other Variables: A Meta-Analytic Review. Journal of Consulting and Clinical Psychology, 68, 438-450. https://doi.org/10.1037/0022-006X.68.3.438

[4] Marziali, E. (1984) Three Viewpoints on the Therapeutic Alliance Scales Similarities, Differences and Associations with Psychotherapy Outcome. The Journal of Nervous and Mental Disease, 172, 417-423. https://doi.org/10.1097/00005053-198407000-00008

[5] McNamara, J. and Gillies, R. (2003) Support Requirements and Effects of Supervision on Telephone Counselors. Journal of Psychologists and Counsellors in Schools, 13, 192-204. https://doi.org/10.1017/S1037291100002880

[6] Othmer, E. and Othmer, S. (2001) The Clinical Interview Using DSM-IV-TR, Volume 1: Fundamentals. American Psychiatric Publishing, Washington DC.

[7] Rezvanpour, S.H. (2001) Phone Counseling Training Manual. State Welfare Organization of Iran, Tehran.

[8] Rezvanpour, S.H. (2007) A Review of the Efficiency and Effectiveness of Phone Counseling, the Role of Telephone Counseling in Iran. State Welfare Organization of Iran, Tehran.

[9] Rosenfield, M. and Smillie, E. (1998) Group Counseling by Telephone. British Journal of Guidance and Counseling, 26, 11-19. https://doi.org/10.1080/03069889808253834

[10] Sadock, B.J. and Sadock, V.A. (2007) Kaplan and Sadock's Synopsis of Psychiatry: Behavioral Sciences/Clinical Psychiatry. 10th Edition, Lippincott Williams \& Wilkins, Philadelphia.

[11] Schegloff, E.A., Jefferson, G. and Sacks, H. (1977) The Preference for Self-Correction in the Organization of Repair in Conversation. Language, 53, 361-382. https://doi.org/10.1353/lan.1977.0041

[12] Shirk, S.R. and Karver, M. (2003) Prediction of Treatment Outcome from Relationship Variables in Child and Adolescent Therapy: A Meta-Analytic Review. Journal of Consulting and Clinical Psychology, 71, 452-464. https://doi.org/10.1037/0022-006X.71.3.452

[13] Bernard, J.M. and Goodyear, R.K. (2009) Fundamentals of Clinical Supervision. 14th Edition, Pearson, Boston, MA.

[14] Dehghani, M., Bolhari, J., Yaghubi, H. and Peiravi, H. (2009) Evaluating Telephone Counseling Satisfaction and Exploring the Instruction and Structure of Counseling Services. Quarterly Journal of Mental Health, 2, 69-76.

[15] Firouzi, M.R. (2007) The Effectiveness of Phone Counseling. State Welfare Organization of Iran, Tehran.

[16] Frawley-O'Dea, M.G. and Sarnat, J.E. (2001) The Supervisory Relationship: A Contemporary Psychodynamic Approach. Guilford Press, New York.

[17] Gabbard, G.O., Beck, J.S. and Holmes, J. (2005) Oxford Textbook of Psychotherapy. Oxford University Press, Oxford.

[18] Ghasemzadeh, F. (2007) The Effectiveness of Phone Counseling. State Welfare Organization of Iran, Tehran.

[19] Hartley, D.E. and Strupp, H.H. (1983) The Therapeutic Alliance: Its Relationship to Outcome in Brief Psychotherapy. In: Masling, J., Ed., Empirical Studies in Analytic Theories, Erlbaum, Hillsdale, NJ, 1-38.

[20] Horvath, A.O. and Symonds, B.D. (1991) Relation between Working Alliance and Outcome in Psychotherapy: A Meta-Analysis. Journal of Counseling Psychology, 
38, 139-149. https://doi.org/10.1037/0022-0167.38.2.139

[21] Johnstone, L. and Dollas, R. (2006) Formulation in Psychology and Psychotherapy: Making Sense of People's Problems. Routledge Press, Abingdon-on-Thames.

[22] Karver, M.S., Handelsman, J.B., Fields, S. and Bickman, L. (2006) Meta-Analysis of Therapeutic Relationship Variables in Youth and Family Therapy: The Evidence for Different Relationship Variables in the Child and Adolescent Treatment Outcome Literature. Clinical Psychology Review, 26, 50-65.

https://doi.org/10.1016/j.cpr.2005.09.001

[23] Lester, D. (1973) Crisis Intervention and Counseling by Telephone. 2nd Edition, Charles C Thomas, Springfield.

Submit or recommend next manuscript to SCIRP and we will provide best service for you:

Accepting pre-submission inquiries through Email, Facebook, LinkedIn, Twitter, etc. A wide selection of journals (inclusive of 9 subjects, more than 200 journals)

Providing 24-hour high-quality service

User-friendly online submission system

Fair and swift peer-review system

Efficient typesetting and proofreading procedure

Display of the result of downloads and visits, as well as the number of cited articles

Maximum dissemination of your research work

Submit your manuscript at: http://papersubmission.scirp.org/

Or contact ojmp@scirp.org 